\title{
Prevalence of anxiety and depression in migraine or tension type headache in patients with or without vertigo
}

\author{
Vaijwade Govind ${ }^{1}$, Kothari Sudhir ${ }^{2}$, Sharma Premendrakumar ${ }^{3}$, Phalgune Deepak $\mathrm{S}^{4 *}$ \\ ${ }^{1}$ Senior Resident, ${ }^{2}$ Professor and HOD, ${ }^{3,4}$ Consultant, ${ }^{1-3}$ Dept. of Neurology, ${ }^{4}$ Dept. of Research, Poona Hospital \& Research Centre, Pune, \\ Maharashtra, India
}

*Corresponding Author: Phalgune Deepak S

Email: dphalgune@gmail.com

\begin{abstract}
Background: Epidemiological studies have established a strong association between primary headaches and psychiatric disorders and the reported prevalence was $66.1 \%$ of depressive and anxiety disorders. The primary objective of this research was to study association of vertigo with anxiety and/or depression in patients of migraine or tension type headache (TTH) whereas secondary objective was to study prevalence of anxiety and depression in migraine or TTH patients.

Methods and Materials: This cross sectional observational study was conducted between September 2015 and February 2017 in patients aged 18 to 70 years of either sex with migraine or TTH with or without vertigo. We used The International classification of headache disorders 3 for diagnosis of migraine, and TTH. Hamilton anxiety rating scale (HAM-A) and Hamilton depression rating scale (HAM-D) were used to assess anxiety and depression respectively. Chi-square test or Fisher's exact test was used to find the association between HAM-A and HAM-D. Odds ratio was calculated to find the chances of occurrence of anxiety or depression in vertigo with the type of headache.

Results: In patients of migraine and TTH with history of vertigo, anxiety and depression was 6.2 times and 2.1 times more prevalent respectively as compared to those without vertigo. Higher percentage of patients with migraine type of headache had depression as compared to TTH patients.

Conclusions: Anxiety and depression is common in patients with migraines and TTH therefore proper diagnosis and treatment of anxiety and depression are needed for improved management of patients of migraine and TTH.
\end{abstract}

Keywords: Anxiety, Depression, Migraine, Tension type headache, Vertigo.

\section{Introduction}

Headaches are amongst the most common disorders of the nervous system. It can be a symptom of a serious lifethreatening disease, such as a brain tumor but in most cases it is a benign disorder such as migraine or tension type headache (TTH). ${ }^{1}$ Migraine is the $3^{\text {rd }}$ most prevalent disease in the world. ${ }^{2}$

Approximately $64 \%-77 \%$ of people have headache at some point in their lives. During each year, on average, $46 \%$ - $53 \%$ of people have headaches. ${ }^{3,4}$ More than $90 \%$ of headaches are primary headaches. ${ }^{4}$ Most of these primary headaches are TTH. ${ }^{5}$ Most people with TTH have "episodic" headaches that come and go. Only $3.3 \%$ of adults have chronic TTH, with headache for more than 15 days in a month. ${ }^{4}$

Approximately $12 \%-18 \%$ of people in the world have migraine. ${ }^{5}$ More women than men experience migraine. In Europe and North America, 5\% - 9\% and12\% - 25\% of men and women experience migraine respectively. ${ }^{3}$ Migraine and TTH can cause substantial levels of disability, not only to patients and their families but also to society. ${ }^{6-10}$ Headache disorders are associated with psychiatric comorbidites, more so in women. ${ }^{6}$ Epidemiological studies have established a strong association between primary headaches and psychiatric disorders ${ }^{7}$ and the reported prevalence was $66.1 \%$ of depressive ${ }^{9}$ and anxiety disorders. ${ }^{7,9,10}$

The reported rates of psychiatric comorbidites ranged between $69 \%-87 \%$ in migraine and $45 \%-56 \%$ in TTH. ${ }^{7,8,11,12}$ Psychiatric disorders as depression and anxiety are comorbid with headache. Several studies stated higher probability of psychiatric disorders among people with migraine. Psychiatric comorbidity complicates the management of patients with headache and it's association leads to poor prognosis. ${ }^{13-16}$

Vertigo is a common complaint in patients of migraine as well as in TTH. It was reported that migraine patients were more likely than TTH to suffer from episodic vertigo $(27 \%$ vs $8 \%){ }^{17}$

The primary objective of this research was to study association of vertigo with anxiety and/or depression in patients of migraine or TTH whereas secondary objective was to study prevalence of anxiety and depression in migraine or TTH patients.

\section{Materials and Methods}

This cross sectional observational study was conducted between September 2015 and February 2017. After approval from the scientific advisory committee and institutional ethics committee, written informed consent was obtained from all the patients. Patients aged 18 to 70 years of either sex with migraine or TTH with or without vertigo who visited neurology specialty clinic at Poona Hospital \& Research Centre were included in the study. Pregnant or lactating women, patients with headache diagnosis other than migraine or TTH, patients with prior history of anxiety, depression or other psychiatric disorders, patients with critical illness such as intensive care unit patients, malignancy, and chronic diseases were excluded from this study. 
Patient's detail history, physical examination, and relevant investigations were recorded. Patients were assessed with rating scales of anxiety or depression. We have used The International classification of headache disorders (ICHD) 3 for diagnosis of migraine, and TTH. ${ }^{12}$ In this study, vertigo was defined as a specific type of dizziness in which the patient has perception of spinning or tilting. Hamilton anxiety rating scale (HAM-A) was used to assess anxiety. HAM-A probes 14 parameters and it took 15-20 minutes to complete the interview and record the score. Each item was scored on a 5-point scale, ranging from $0=$ not present to $4=$ severe. Score categories were made $0-14,15-17,18-24,25-30$ and $>30$ as normal, mild anxiety, moderate anxiety, severe anxiety and very severe anxiety respectively. The sensitivity and specificity of HAM-A is $85.7 \%$ and $63.5 \%$ respectively. ${ }^{18}$

Hamilton depression rating scale (HAM-D) was used to assess depression. Although the HAM-D form lists 21 items, the scoring is based on the first 17. It also took 15-20 minutes to complete the interview and record the score. Eight items scored on a 5-point scale, ranging from $0=$ not present to $4=$ severe. Nine are scored from 0-2. Score categories were made $0-7,8-13,14-18,19-22$ and $>22$ as normal, mild depression, moderate depression, severe depression and very severe depression respectively. The sensitivity and specificity of HAM-D is $86.4 \%$ and $92.2 \%$ respectively. ${ }^{19}$

On the basis of a previously published study, ${ }^{3}$ a sample size of 195 patients was calculated by using the formula by Charan and Biswas ${ }^{20}$ with $80 \%$ power and $5 \%$ probability of Type I error to reject null hypothesis. We have included 206 patients in the study to validate the results.

Data collected were entered in the Excel 2007 and analysis of data was done using Statistical Package for Social Sciences version 20 (Chicago- IL, USA) for MS Windows. Qualitative data variables are expressed by using frequency and percentage (\%). Chi-square test or Fisher's exact test was used to find the association between HAM-A and HAM-D with various qualitative data variables. Odds ratio was calculated to find the chances of occurrence of anxiety or depression in vertigo with the type of headache. The confidence limit for significance was fixed at $95 \%$ level with $\mathrm{p}$-value $<0.05$.

\section{Results}

This study was undertaken to find association of vertigo with anxiety and/or depression in patients of migraine or
TTH and prevalence of anxiety and depression in migraine or TTH patients with or without vertigo.

Of the total 206 patients 3(1.5\%), 81(39.3\%), $45(21.8 \%), 58(28.2 \%)$ and $19(9.2 \%)$ were between the age group of 18-20, 21-30, 31-40, 41-50, and 51-70 years respectively. Mean age was $35.53( \pm 10.13)$ years. In this research $128(62.1 \%)$ were females and $78(37.9 \%)$ males. One hundred eight (52.4\%) patients had TTH and $98(47.6 \%)$ had migraine type headache. One hundred sixty eight $(81.6 \%)$, and $134(65 \%)$ had history of vertigo and sleep disturbance respectively. Eighty nine (43.2\%), 63 $(30.6 \%)$ and $54(26.2 \%)$ patients had no anxiety, mild to moderate and severe to very severe type of anxiety respectively according to HAM-A scale. Seventy six (36.9\%), 25 (12.1\%) and $105(51.0 \%)$ patients had no depressive disorder, mild to moderate and severe to very severe type of depressive disorder respectively according to HAM-D scale.

There was no statistically significant difference between type of headache and HAM-A score (Table 1). There was no statistically significant difference between $\mathrm{H} / \mathrm{O}$ vertigo and HAM A score (Table 2). There was statistically significant difference between type of headache and depression (Table 3). Higher percentage of patients $(73.5 \%)$ of migraine type headache had depression as compared to patients $(53.7 \%)$ of TTH type headache. As evident from Table 4, there was statistically significant difference between history of vertigo and depression. Higher percentage of patients who had $\mathrm{H} / \mathrm{O}$ vertigo had depression (70.8\%) as compared to patients who had no $\mathrm{H} / \mathrm{O}$ vertigo (28.9\%). As evident from Table 5, 45/85 $(52.9 \%)$ patients had both depression and anxiety in TTH patients with vertigo as compared to patients who did not have vertigo 8/23 (34.8\%) which was statistically significant with odds ratio of 2.1. As depicted in Table 6, 52/ 83 $(62.6 \%)$ patients had both depression and anxiety in migraine type of headache with vertigo as compared to patients who did not have vertigo $3 / 15(20.0 \%)$ which was statistically significant with odds ratio of 6.2 . The TTH patients with vertigo had 2.1 times more chances of occurrence of both anxiety and depression whereas migraine type of headache patients with vertigo had 6.2 times more chances of occurrence of both anxiety and depression.

There was no statistically significant difference between occurrence of vertigo and psychiatric comorbidity in TTH patients, also there was no statistically significant difference between occurrence of vertigo and psychiatric comorbidity in migraine patients.

Table 1: Association of anxiety with type of headache.

\begin{tabular}{|c|c|c|c|c|c|}
\hline \multirow{2}{*}{$\begin{array}{c}\text { Type of } \\
\text { headache }\end{array}$} & $\begin{array}{c}\text { Normal } \\
\mathbf{n}(\%)\end{array}$ & $\begin{array}{c}\text { Mild - moderate } \\
\mathbf{n}(\boldsymbol{\%})\end{array}$ & $\begin{array}{c}\text { Severe- very } \\
\text { severe n(\%) }\end{array}$ & \multirow{2}{*}{$\begin{array}{c}\text { Total } \\
\mathbf{n}(\%)\end{array}$} & \multirow{2}{*}{-value } \\
\hline Tension type & $53(49.1 \%)$ & $29(26.8 \%)$ & $26(24.1 \%)$ & $108(100 \%)$ & 0.208 \\
\hline Migraine & $36(36.7 \%)$ & $34(34.7 \%)$ & $28(28.6 \%)$ & $98(100 \%)$ & \\
\hline Total & $89(43.2 \%)$ & $63(30.6 \%)$ & $54(26.2 \%)$ & $206(100 \%)$ & \\
\hline
\end{tabular}

Chi square test was used

HAM-A - Hamilton anxiety rating scale 
Table 2: Association of anxiety with history of vertigo.

\begin{tabular}{|c|c|c|c|c|c|}
\hline \multirow{2}{*}{$\begin{array}{c}\text { History of } \\
\text { Vertigo }\end{array}$} & $\begin{array}{c}\text { Normal } \\
\text { n (\%) }\end{array}$ & $\begin{array}{c}\text { Mild - moderate } \\
\text { n (\%) }\end{array}$ & $\begin{array}{c}\text { Severe- very } \\
\text { severen (\%) }\end{array}$ & \multirow{2}{*}{$\begin{array}{c}\text { Total } \\
\text { n (\%) }\end{array}$} & \multirow{2}{*}{ p-value } \\
\hline Present & $71(42.3 \%)$ & $52(31.0 \%)$ & $45(26.7 \%)$ & $168(100 \%)$ & 0.843 \\
\hline Absent & $18(47.4 \%)$ & $11(28.9 \%)$ & $9(23.7 \%)$ & $38(100 \%)$ & \\
\hline Total & $89(43.2 \%)$ & $63(30.6 \%)$ & $54(26.2 \%)$ & $206(100 \%)$ & \\
\hline
\end{tabular}

Chi square test was used

HAM-A - Hamilton anxiety rating scale

Table 3: Association of depression with type of headache

\begin{tabular}{|c|c|c|c|c|c|}
\hline \multirow{2}{*}{$\begin{array}{c}\text { Type of } \\
\text { headache }\end{array}$} & \multicolumn{3}{|c|}{ HAM-D } & \multirow{2}{*}{$\begin{array}{c}\text { Total } \\
\text { n (\%) }\end{array}$} & \multirow{2}{*}{ p-value } \\
\cline { 2 - 5 } & $\begin{array}{c}\text { Normal } \\
\text { n(\%) }\end{array}$ & $\begin{array}{c}\text { Mild - moderate } \\
\text { n (\%) }\end{array}$ & $\begin{array}{c}\text { Severe- very } \\
\text { severe n (\%) }\end{array}$ & & \\
\hline Tension type & $50(46.3 \%)$ & $6(5.6 \%)$ & $52(48.1 \%)$ & $108(100 \%)$ & 0.001 \\
\hline Migraine & $26(26.5 \%)$ & $19(19.4 \%)$ & $53(54.1 \%)$ & $98(100 \%)$ & \\
\hline Total & $76(36.9 \%)$ & $25(12.1 \%)$ & $105(51.0 \%)$ & $206(100 \%)$ & \\
\hline
\end{tabular}

Chi square test was used

HAM-D - Hamilton depression rating scale

Table 4: Association of depression with history of vertigo

\begin{tabular}{|c|c|c|c|c|c|}
\hline \multirow{2}{*}{$\begin{array}{c}\text { History of } \\
\text { Vertigo }\end{array}$} & \multicolumn{3}{|c|}{ HAM-D } & \multirow{2}{*}{$\begin{array}{c}\text { Total } \\
\text { n (\%) }\end{array}$} & \multirow{2}{*}{-value } \\
\cline { 2 - 5 } & $\begin{array}{c}\text { Normal } \\
\text { n (\%) }\end{array}$ & $\begin{array}{c}\text { Mild - moderate } \\
\text { n (\%) }\end{array}$ & $\begin{array}{c}\text { Severe- very } \\
\text { severe n (\%) }\end{array}$ & & \\
\hline Present & $49(29.2 \%)$ & $24(14.3 \%)$ & $95(56.5 \%)$ & $168(100 \%)$ & $<0.001$ \\
\hline Absent & $27(71.1 \%)$ & $1(2.6 \%)$ & $10(26.3 \%)$ & $38(100 \%)$ & \\
\hline Total & $76(36.9 \%)$ & $25(12.1 \%)$ & $105(51.0 \%)$ & $206(100 \%)$ & \\
\hline
\end{tabular}

Chi-square test was used.

HAM-D - Hamilton depression rating scale

Table 5: Anxiety, depression in TTH

\begin{tabular}{|c|c|c|c|c|}
\hline Anxiety / Depression & \multicolumn{2}{|c|}{ Tension type headache } & \multirow{2}{*}{$\begin{array}{c}\text { Odds ratio } \\
\text { and C.I }\end{array}$} & \multirow{2}{*}{ p-value } \\
\cline { 2 - 3 } & $\begin{array}{c}\text { Vertigo } \\
\text { present n (\%) }\end{array}$ & $\begin{array}{c}\text { Vertigo absent } \\
\mathbf{n}(\boldsymbol{\%})\end{array}$ & - \\
\hline Only depression & $5(5.9 \%)$ & $0(0 \%)$ & - & \\
\hline Only anxiety & $0(0 \%)$ & $2(8.7 \%)$ & 2.1 \\
& Both present & $45(52.9 \%)$ & $8(34.8 \%)$ & \multirow{2}{*}{0.025} \\
\hline Both absent & $35(41.2 \%)$ & $13(56.5 \%)$ & $(0.78-5.59)$ & \\
\hline Total & $85(100 \%)$ & $23(100 \%)$ & & \\
\hline
\end{tabular}

Fisher's exact test was used.

TTH - Tension type headache

Table 6: Anxiety, depression in migraine.

\begin{tabular}{|c|c|c|c|c|}
\hline \multirow{2}{*}{ Anxiety / Depression } & \multicolumn{2}{|c|}{ Migraine type headache } & \multirow{2}{*}{} \\
\cline { 2 - 4 } & $\begin{array}{c}\text { Vertigo } \\
\text { present n (\%) }\end{array}$ & $\begin{array}{c}\text { Vertigo absent } \\
\text { n (\%) }\end{array}$ & $\begin{array}{c}\text { Odds ratio } \\
\text { and C.I }\end{array}$ & p-value \\
\hline Only depression & $17(20.5 \%)$ & $0(0 \%)$ & - & \\
\hline Only anxiety & $0(0 \%)$ & $7(46.7 \%)$ & - & \\
\hline Both present & $52(62.6 \%)$ & $3(20.0 \%)$ & 6.2 & $<0.001$ \\
\hline Both absent & $14(16.9 \%)$ & $5(33.3 \%)$ & $(1.31-29.11)$ & \\
\hline Total & $83(100 \%)$ & $15(100 \%)$ & & \\
\hline
\end{tabular}

Fisher's exact test was used. 


\section{Discussion}

Psychiatric disorders are frequently seen in patients of migraine and TTH. This observational study was conducted in 206 patients to find association of vertigo with anxiety and/or depression in patients of migraine or TTH and prevalence of anxiety and depression in migraine or TTH patients with or without vertigo.

In this study, both anxiety and depression was found in $53 / 108(49.1 \%)$ and 55/98(56.1\%) patients in TTH and migraine type of headache respectively. Bera et al., reported psychiatric co-morbidity in subjects of migraine and TTH was $25 / 40(62.5 \%)$ and $24 / 40(60 \%)$ respectively with no significant differences between the groups and major depressive disorders 15/40 (37.5\%) and 12/40 (30 \%) respectively. ${ }^{21}$

In this research, anxiety was found in 55/108 (50.9\%) and 62/98 $(63.3 \%)$ patients in TTH and migraine type of headache respectively whereas depression was found in $58 / 108(53.7 \%)$ and $72 / 98(73.5 \%)$ patients in TTH and migraine type of headache respectively. Desai and Pandya reported depressive disorder in $46 \%$ of patients with migraine, $47.8 \%$ of patients with TTH whereas anxiety was present in $22 \%$ of patients with migraine, $13 \%$ of patients with TTH. ${ }^{22}$ Song et al. conducted a population based study, which reported among 570 TTH patients, 54(9.5\%) had anxiety and $24(4.2 \%)$ had depression, $44(7.7 \%)$ had anxiety alone, $14(2.5 \%)$ had depression alone, and 10(1.8\%) had both anxiety and depression. ${ }^{23}$

We found 119/168 (70.8\%) headache patients with vertigo had depression, 50/85 (58.8\%) TTH with vertigo, $69 / 83(83.1 \%)$ migraine with vertigo had depression. Neuhauser et al., reported the prevalence of migraine was higher in the vertigo clinic group (38\%) compared with the age and sex matched control group $(24 \%, P<0.01)$. The prevalence of migrainous vertigo was $7 \%$ in the vertigo clinic group, and $9 \%$ in the migraine clinic group. ${ }^{24} \mathrm{We}$ also found significant association of occurrence of both anxiety and depression with history of vertigo in patients of headache.

In this study, three (1.5\%), 81(39.3\%), 45(21.8\%), $58(28.2 \%), 19(9.2 \%)$ were below 20 years, 21 to 30 years, $31-40$ years, 41 to 50 years and above 50 years respectively. Mean age of the patients was 35.5 years. Bhuvana ${ }^{5}$ reported that $78 \%$ of headache patients were in age group 20 to 40 years and mean age was 32.0 years. This difference with their study was due to the difference in inclusion of the age groups, ranged from 18 years to more than 50 years, and differences in the methodology. Jain et al. reported that of 202 patients 33(16.3\%), 86( 42.6\%), 52(25.7\%), 15(7.4\%) and $16(8.0 \%)$ were below the age of 21 years, 21-30 years, $31-40$ years, $41-50$ years and $\geq 51$ years respectively. ${ }^{25}$ In our study $62.1 \%$ were females and $37.9 \%$ males. Bhuvana ${ }^{5}$ reported that females were $73 \%$ and males $27 \%$.

Bhuvana reported that tension-type of headache was found to be the commonest type of headache with a prevalence of $89 \%$ followed by migraine headache $(10 \%)$ and least were cluster headache $(1 \%) .^{5}$ Stovner et al,.$^{4}$ reviewed 31 studies of adult population from European countries and summarized that prevalence of migraine and TTH was $14.7 \%$ and $62.6 \%$ respectively. Kandil et al., ${ }^{26}$ reported that TTH 640/1462 (43.8\%) had high of prevalence followed by migraine 496(33.9\%).

Bhuvana reported that the most common psychiatric comorbidity among the patients presenting with headache were mood disorders (28\%), anxiety disorder (16\%) and major depressive disorders $(26 \%) .{ }^{5}$ Verri et al. ${ }^{27}$ reported that $25.8 \%$ had depression, among the patients presenting with headache; Merikangas et al., did not find any significant difference in the frequency of major depression among the patients with TTH as compared to headaches free control. $^{28}$

There are few limitations in the study. We included TTH and migraine type headache, but other subtypes of headache patients were not included in the study. Patients with history and characteristics of vertigo sub-groups as acute vertigo, central or peripheral vertigo were not included in the study. Further prospective studies with larger sample size are required to validate our findings.

\section{Conclusions}

Combined anxiety and depression was 6.2 times more prevalent in patients of migraine with history of vertigo as compared to those without vertigo. Combined anxiety and depression was 2.1 times more prevalent in patients of TTH with vertigo as compared to those without vertigo. Higher percentage of patients with migraine type of headache had depression as compared to TTH patients. History of vertigo was associated with depression.

\section{Conflict of Interest: None.}

\section{References}

1. Jensen R, Rasmussen BK. Burden of headache. Expert review of pharmacoeconomics \& outcomes research. 2004;4:353-9.

2. Steiner TJ, Birbeck GL, Jensen RH, Katsarava Z, Stovner LJ, Martelletti P. Headache disorders are third cause of disability worldwide. J Headache Pain 2015;16:1-3.

3. Manzoni GC, Stovner LJ. Epidemiology of headache. Handbook Clin Neurol 2010;97:3-22.

4. Stovner LJ, Andree C. Prevalence of headache in Europe: a review for the Eurolight project. J Headache Pain 2010;11:289-99.

5. Bhuvana RC. Prevalence of psychiatric co-morbidity in patients presenting with chronic daily headache: a hospital based cross sectional study. Int J Res Med Sci 2017;5:321-5.

6. Stovner LJ, Hagen K, Jensen R, Katsarava Z, Lipton RB, Scher AI, et al. The global burden of headache: a documentation of headache prevalence and disability worldwide. Cephalalgia 2007;27:193-210.

7. Schwartz BS, Stewart WF, Simon D, Lipton RB. Epidemiology of tension-type headache. JAMA 1998;279:3813.

8. Boardman HF, Thomas E, Croft PR, Millson DS. Epidemiology of headache in an English district. Cephalalgia 2003;23:129-37.

9. Olesen J, Leonardi M. The burden of brain diseases in Europe. Eur J Neurol 2003;10:471-7.

10. Morillo LE, Alarcon F, Aranaga N, Aulet S, Chapman E, Conterno L, et al. Prevalence of migraine in Latin America. 
Headache. J Head Face Pain 2005;45:106-17.

11. Steiner TJ. Lifting the burden: the global campaign against headache. Lancet Neurol 2004;3:204-5.

12. Headache Classification Subcommittee of the International Headache Society. Int Classification Headache Disorders. Cephalalgia 2004;24:9-160.

13. O'brien BE, Goeree R, Streiner D. Prevalence of migraine headache in Canada: a population-based survey. Int $J$ Epidemiol 1994;23:1020-6.

14. Schwartz BS, Stewart WF, Lipton RB. Lost workdays and decreased work effectiveness associated with headache in the workplace. J Occupational Environmen Med 1997;39:320-7.

15. Lipton RB, Stewart WF, Diamond S, Diamond ML, Reed M. Prevalence and burden of migraine in the United States: data from the American Migraine Study II. Headache: J Head Face Pain 2001;41:646-57.

16. Lipton RB, Scher AI, Kolodner K, Liberman J, Steiner TJ, Stewart WF et al. Migraine in the United States Epidemiology and patterns of health care use. Neurol 2002;58:885-94.

17. Kayan A, Hood JD. Neuro-otological manifestations of migraine. Brain 1984;107:1123-42.

18. Kummer A, Cardoso F, Teixeira AL. Generalized anxiety disorder and the Hamilton Anxiety Rating Scale in Parkinson's disease. Arq Neuropsiquiatr 2010;68:495-501.

19. Strik JJMH, Honig A, Lousberg R, Denollet J. Sensitivity and specificity of observer and self-report questionnaires in major and minor depression following myocardial infarction. Psychosom 2001;42:423-8.

20. Charan J, Biswas T. How to calculate sample size for different study designs in medical research?. Indian J Psychol Med 2013;35:121-26.
21. Bera SC, Khandelwal SK, Sood M, Goyal V. A comparative study of psychiatric comorbidity, quality of life and disability in patients with migraine and tension type headache. Neurol India 2014;62:516-20.

22. Desai SD, Pandya RH. Study of psychiatric comorbidity in patients with headache using a short structured clinical interview in a rural neurology clinic in Western India. $J$ Neurosci Rural Pract 2014;5:S39-S42.

23. Song TJ, Cho SJ, Kim WJ, Yang KI, Yun CH, Chu MK. Anxiety and Depression in Tension-Type Headache: A Population-Based Study. PloSOne 2016;11(10):e0165316.

24. Neuhauser H, Leopold M, von Brevern M, Arnold G, Lempert $\mathrm{T}$. The interrelations of migraine, vertigo, and migrainous vertigo. Neurol 2001;56:436-41

25. Jain AP, Chauhan B, Bhat AD. Sociodemographic and clinical profile of headache-a rural hospital-based study. Hypertension. J Indian Acad Clin Med 2007;8:26-8

26. Kandil MR, Hamed SA, Fadel KA, Youssef AH, Abd E Hamed MA, Mohamed KO. Epidemiology of tension-type headache (TTH) in Assuit Governorate, Egypt. J Neurol Neurosci 2014;5(1):2

27. Verri AP, Proietti CA, Galli C, Granella F, Sandrini G, Nappi G. Psychiatric comorbidity in chronic daily headache. Cephalalgia 1998;18:45-9.

28. Merikangas KR, Merikangas JR, Angst J. Headache syndromes and psychiatric disorders: association and familial transmission. J Psychiatr Res 1993;27:197-210.

How to cite this article: Govind V, Sudhir K, Sharma PK, Phalgune DS. Prevalence of anxiety and depression in migraine or tension type headache in patients with or without vertigo. India J Neurosci 2019;5(2):59-63. 